\title{
A alegoria em J.R.R. Tolkien: entre as Ciências da Religião e a Filosofia Perene
}

\author{
Diego Klautau' \\ Carlos Ribeiro Caldas Filho
}

\section{Resumo}

O ensaio On Fairy-Stories de J.R.R. Tolkien (1892-1973) é resultado da conferência de 1939 para a Universidade de St. Andrews e revisado para publicação em 1947. Neste texto, Tolkien dialoga com duas figuras importantes para as Ciências da R)eligião, Max Müller (1823-1900) e Andrew Lang (1844-1912). O primeiro é um dos fundadores da ciência da religião, a partir de suas pesquisas em filologia, enfatizando as relações entre linguagem, mito e religião. O segundo foi antropólogo e folclorista, igualmente discutindo as relações entre mito e religião. Neste diálogo, Tolkien estabelece críticas a ambos, fundamentalmente relativas à concepção de alegoria, e indica uma proposta teórica que resgata elementos da filosofia perene, enfatizando elementos de Platão, Aristóteles, Agostinho e Tomás de Aquino.

Palavras-chave: J.R.R. Tolkien, Max Müller, Andrew Lang, Ciências da Religião, Alegoria.

\section{The allegory in J.R.R. Tolkien: between the Sciences of Religion and Perenive Philosophy}

\begin{abstract}
The essay On Fairy-Stories by JRR Tolkien (1892-1973) is the result of a 1939 conference at the University of St. Andrews and revised for publication in 1947. In this text, Tolkien dialogues with two important figures in the Religious Studies, Max Müller (1823-1900) and Andrew Lang (1844-1912). The former is one of the founders of the Religious Studies, drawing on his research in philology, emphasizing the relationships between language, myth and religion. The second was an anthropologist and folklorist, who also discussed the relationship between myth and religion. In this dialogue, Tolkien criticizes both, fundamentally related to the conception of allegory, and indicates a
\end{abstract}

Doutor em Ciências da Religião pela PUC-SP. Pós doutorando em Ciências da Religião pela PUC-Minas. Professor do Centro Universitário FEI. E-mail: dklautau@gmail.com Doutor em Ciências da Religião pela Universidade Metodista de São Paulo. Professor do Programa de Pós-Graduação em Ciências da Religião da PUC-Minas. E-mail: crcaldas2009@hotmail.com 
theoretical proposal that rescues elements of perennial philosophy, highlighting elements from Plato, Aristotle, Augustine and Thomas Aquinas.

Key Words: J.R.R. Tolkien, Max Müller, Andrew Lang, Religious Studies, Allegory

\section{La alegoría en J.R.R. Tolkien: entre las Ciencias de la Religión y la Filosofía Pereniva}

\section{Resumen}

El ensayo On Fairy-Stories de JRR Tolkien (1892-1973) es el resultado de una conferencia de 1939 en la Universidad de St. Andrews y revisado para su publicación en 1947. En este texto, Tolkien dialoga con dos figuras importantes de las Ciencias de la Religión , Max Müller (1823-1900) y Andrew Lang (1844-1912). El primero es uno de los fundadores de la ciencia de la religión, basado en su investigación en filología, enfatizando las relaciones entre lenguaje, mito y religión. El segundo fue un antropólogo y folclorista, que también discutió la relación entre mito y religión. En este diálogo, Tolkien critica a ambos, fundamentalmente relacionados con la concepción de la alegoría, e indica una propuesta teórica que rescata elementos de la filosofía perenne, destacando elementos de Platón, Aristóteles, Agustín y Aquino.

Palabras clave: J.R.R. Tolkien, Max Müller, Andrew Lang, Ciencias de la Religión, Alegoría

\section{Introdução}

John Ronald Reuel Tolkien (1892-1973) foi um dos mais importantes escritores do século XX. Nascido no Estado Livre de Orange (atual África do Sul), era filho de britânicos e viveu na Inglaterra, entre Birmingham, Oxford e Bournemouth, desde seus quatro anos até sua morte. Órfão de pai aos quatro anos e de mãe aos doze, ele e o irmão foram criados pelo sacerdote católico Francis Xavier Morgan, um discípulo do Cardeal John Henry Newman. Casou-se com Edith Bratt em 1916 e teve quatro filhos. Participou na primeira guerra mundial como tenente, responsável pela comunicação do front na Batalha do Somme. Foi professor catedrático na Universidade de Oxford entre 1925 e 1959, primeiro de Anglo-Saxão (19251945) e depois de Língua e Literatura Inglesa (1945-1959), período no qual publicou artigos que se transformaram em referência de pesquisa e realizou conferências que impactaram sua área de estudos. Entre as mais importantes obras científicas estão a edição do poema medieval Sir Gawain and the Green Knight (1925), a conferência sobre o poema anglo-saxão Beowulf denominada Beowulf: The Monsters and the Critics (1936) e a palestra, posteriormente ampliada em ensaio, sobre a essência das estórias de fadas On Fairy-Stories (1939). Recebeu dois títulos de doutor honoris causa em Letras no ano de 1954, tanto 
pela Universidade de Liége quanto pela Universidade Nacional da Irlanda, e um terceiro título pela Universidade de Oxford em 1972, no mesmo ano que foi homenageado com a medalha de Comandante da Ordem do Império Britânico, concedida pela Rainha Elizabeth II.

Apesar da biografia de relativo sucesso, nenhum dos fatos acima é a causa direta de sua importância na literatura. Entre seus afazeres acadêmicos, sua vida familiar exigente e seus compromissos com sua religião católica, Tolkien escreveu O Hobbit (1937) e O Senhor dos Anéis (1954-55). Tais obras se transformaram em um fenômeno editorial logo nos primeiros anos de sua publicação e continuaram a entusiasmar leitores e pesquisadores ao longo das décadas vindouras. Formaram-se inúmeras sociedades, associações e grupos de leituras de fãs, entre as mais importantes estão a inglesa Tolkien Society (1969) e a americana Mythopoeic Society (1971). Do mesmo modo, multiplicaram-se investigações tolkienistas por meio de artigos acadêmicos, dissertações e teses em Literatura, História, Filosofia e Teologia em vários países. Após a morte de J.R.R. Tolkien, seu filho mais novo Christopher Tolkien (1924-2020) editou uma série de livros póstumos, tanto sobre a produção ficcional quanto de suas pesquisas acadêmicas, entre eles O Silmarillion (1977) e a coleção de doze volumes The History of Middle-earth (1983-1996). Christopher também auxiliou o autor Humphrey Carpenter na pesquisa para a escrita de J.R.R. Tolkien: Uma Biografia (1977) e na edição e seleção de As Cartas de J.R.R. Tolkien (1981).

A literatura da Terra-média, o continente fictício no qual se passam as narrativas de Tolkien, inspirou ambientações de Role Playing Game, jogos eletrônicos e uma nova frente de produção literária de fantasia. Com o advento da internet, multiplicaram-se fóruns de discussão on-line, páginas dedicadas ao tema e canais de youtubers. No início do século XXI, os filmes dirigidos por Peter Jackson, primeiro de O Senhor dos Anéis (2001-2003) depois de O Hobbit (2012-2014), colecionaram estatuetas do Oscar e bilhões de dólares. Em 2018 a Amazon anunciou o lançamento de uma série a ser lançada por streaming sobre a obra de Tolkien, com o orçamento de 1 bilhão de dólares, com previsão para cinco temporadas e com estreia prevista para meados de 2021 .

Entre as referências intelectuais citadas diretamente em suas obras acadêmicas, muitas vezes como alvo de crítica, estão o filólogo Max Müller ${ }^{3}$

Filólogo alemão (1823-1900), é-lhe atribuída a criação do nome "Ciência da Religião" enquanto disciplina própria em 1867. Filólogo, tradutor e orientalista especializado em tradições hindus, contratado pela universidade de Oxford desde 1854, publicou em 1856 


\section{Diego Klautau \\ Carlos Ribeiro Caldas Filho}

(1823-1900) e o antropólogo e folclorista Andrew Lang ${ }^{4}$ (1844-1912), especialmente quando se trata de teorias sobre o mito, a linguagem e a religião. Como interlocutores mais afins conceitualmente aparecem G.K. Chesterton (1874-1936) e Christopher Dawson (1889-1970), ambos eruditos católicos romanos nascidos na Inglaterra e com uma relevante atuação pública em questões filosóficas e teológicas, envolvidos pelo neotomismo estimulado pelo Papa Leão XIII em fins do século XIX. De maneira mais próxima, houve a amizade com o escritor e professor C.S. Lewis (1898-1963), colega de Oxford por décadas, onde formaram o grupo de leitura Inklings, composto por literatos, filósofos e teólogos e interessados em produção ficcional e cristianismo. A importância de Tolkien durante o processo de conversão de Lewis à fé cristã é célebre, ainda que este tenha permanecido como leigo na Igreja da Inglaterra, não compartilhando com Tolkien seu catolicismo romano. Da mesma forma, é famosa a relevância fundamental de Lewis como encorajador de Tolkien para a composição de $O$ Senhor dos Anéis. Entre as fontes reconhecidas pelo próprio autor de suas obras literárias e suas línguas inventadas estão o Beowulf anglo-saxão, os Eddas islandeses, a Atlântida de Platão, a literatura arturiana medieval, a Bíblia cristã, o Kalevala finlandês e o Mabinogion galês.

Apesar de ser mais conhecido como autor de literatura fantástica, como O Hobbit (1937) e O Senbor dos Anéis (1954-55), J.R.R. Tolkien desenvolveu uma carreira na Universidade de Oxford, primeiro na cadeira de Anglo-Saxão e depois na de Língua e Literatura inglesa. Nesse contexto, produziu artigos de pesquisa, orientou monografias e escreveu livros sobre diversos aspectos relacionados à filologia e à teoria literária. Sua pertença ao catolicismo, especificamente ligado ao movimento de renovação da Igreja Romana no Reino Unido no início do século XX, está relacionada ao Cardeal Newman (1801-1890) e a G.K. Chesterton (1874-1936), constituintes do cenário intelectual e religioso da época. Assim, por suas atividades profissionais universitárias, sua atuação como ficcionista e sua identidade católica, encontramos elementos teóricos sobre as relações entre linguagem, mito e religião, componentes privilegiados da área de pesquisa denominada Ciência da Religião.

o livro Mitologia Comparada (CROATTO, 2001), em 1861 Lectures on the Science of Language e em 1870 uma obra com o título Ciência da Religião, que definia em uma perspectiva filológica e comparativa o estudo das religiões (USARSKI, 2006).

4 Folclorista escocês (1844-1912), ao qual se atribui a descoberta de uma relativa presença da crença em um ser Supremo, criador e indicador ético, em muitos povos não letrados (FIROLAMO, PRANDI, 1999). 
Neste artigo, investigamos o ensaio On Fairy-Stories, proferido incialmente em 1939 como conferência e revisado e expandido para publicação em 1947. Neste texto, Tolkien apresenta sua teoria acerca das fairy stories, as estórias de fadas, desde sua definição, origem e função. Como nosso objetivo é cotejar alguns aspectos da teoria tolkieniana com as Ciências da Religião, incialmente analisamos trechos do ensaio nos quais Tolkien dialoga tanto com Max Müller (1823-1900), quanto com Andrew Lang (1844-1912), ambos os autores referências tanto nas Ciências da Religião quanto no estudo do Folclore Comparado. Por fim, indicamos a crítica tolkieniana da alegoria como ferramenta explicativa tanto do fenômeno religioso quanto da arte literária, evidenciando alguns pontos que se alinham com a o pensamento de Tomás de Aquino, cuja relação se deriva tanto do contexto histórico inglês do neotomismo da intelectualidade católica quanto pela investigação própria de Tolkien em suas reflexões sobre linguagem e realidade.

\section{Max Müller e Tolkien}

O primeiro elemento a considerar em Müller é a afirmação da mitologia como uma doença da linguagem, ou seja, como uma consequência imprópria, desviante de sua natureza, um acontecimento incontornável derivado da falha de percepção das coisas e sua relação com a mente e a linguagem. Tal perspectiva é própria da filosofia moderna, da qual Müller integra em sua perspectiva teórica.

A mitologia, que foi a perdição do mundo antigo, é na verdade uma doença da linguagem. Um mito significa uma palavra, mas uma palavra à qual, por ser um nome ou um atributo, se permitiu assumir uma existência mais substancial. A maioria dos deuses gregos, romanos, indianos e outros deuses pagãos nada mais são do que nomes poéticos, aos quais foi permitido assumir gradualmente uma personalidade divina jamais contemplada por seus inventores originais (MÜLLER, 1885, p. 12). (tradução própria).

Seguindo essa concepção, a atribuição de uma personalidade ao nome dos deuses é uma consequência imprevista e inescapável no processo da linguagem, sendo essa junção entre nome e personalidade normalmente relacionada a um fenômeno natural, com ênfase fundante nos mitos solares, mas também as chuvas, a lua ou o mar. Em outras palavras, a passagem desviante do nomina (nomes) para o numina (sagrado) é a base da mitologia e da religião. Assim, a mitologia é um resultado necessário da deficiência da 


\section{Diego Klautan \\ Carlos Ribeiro Caldas Filho}

percepção e da linguagem de adequar realidade e mente de forma imediata. Essa é a questão que acompanha a filosofia moderna desde a crise do nominalismo no século XIV, quanto a perspectiva gnosiológica aristotélicatomista, denominada grosso modo de realista, entra em declínio enquanto teoria hegemônica no ambiente universitário.

Durante a Idade Média, a polêmica entre Nominalismo e Realismo, que agitou a igreja por séculos e finalmente preparou o caminho para a Reforma, foi novamente, como seu próprio nome mostra, uma polêmica sobre nomes, sobre a natureza da linguagem e a relação das palavras com nossas concepções por um lado, e, por outro, com as realidades do mundo exterior. Os homens eram chamados de hereges por acreditarem que palavras como justiça ou verdade expressavam apenas concepções de nossa mente, e não coisas reais andando em plena luz do dia. (MÜLLER, 1885, p. 12-13). (tradução própria).

Para Tolkien, inspirado no neotomismo na Igreja Católica promovido pelo Papa Leão XIII (1810-1903), a perspectiva realista se tornou elemento fundamental (MANNI \& SHIPPEY, 2014, p.21-29) em sua teoria, refutando a perspectiva de Müller da mitologia como doença da linguagem. Ao comentar sobre as relações entre mito e linguagem na análise das estórias de fadas, Tolkien afirma:

A Filologia foi destronada do alto posto que antes tinha nessa corte de inquérito. A visão que Max Müller tinha da mitologia como uma "doença da língua” pode ser abandonada sem remorso. A mitologia não é uma doença de forma alguma, embora possa, como todas as coisas humanas, ficar adoentada. Poder-se-ia muito bem dizer que o pensamento é uma doença da mente. Estaria mais perto da verdade dizer que as línguas, em especial as línguas europeias modernas, são uma doença da mitologia. (TOLKIEN, 2020, p. 34).

A posição de que a mitologia (a fabricação de imagens associadas a realidades como forma de explicação do mundo) é uma doença da linguagem (uma degeneração da explicitação da realidade) é contestada. A única maneira de existir linguagem é através da fabricação de imagens (phantasia). Por isso, as línguas todas são derivadas (doenças) da mitologia, da mesma forma que o pensamento é derivado da mente, porque é resultado direto de operação em sua própria natureza.

Assim, Tolkien propõe uma inversão gnosiológica em relação à teoria de Müller. A partir do realismo, como à mente humana é possível abstrair as 
essências inteligíveis, formando os universais, é mais adequado afirmar que o próprio pensamento que é uma "doença" da mente, no sentido de ser uma consequência posterior e não um mal funcionamento. Como a abstração das essências necessita da formação das imagens, e todo o trabalho da imaginação, é com base nessas imagens que construímos mentalmente tanto os conceitos formais quanto a maneira de exprimir tais conceitos, isto é, a linguagem. Dito de outra forma, a mente percebe as coisas e as generaliza a partir de imagens formadas na mente, abstraindo daí suas essências e, assim, necessita de uma linguagem para expressá-las. Nesse sentido, a mitologia (o conjunto de imagens) é a base para a linguagem.

Quanto mais perto o assim chamado "mito da natureza", ou alegoria dos grandes processos da natureza, está de seu suposto arquétipo, menos interessante ele é e, de fato, menos é um mito capaz de lançar qualquer iluminação que seja sobre o mundo. Vamos assumir para o momento, como essa teoria assume, que nada realmente existe de correspondente aos "deuses" da mitologia: nenhuma personalidade, apenas objetos astronômicos ou meteorológicos. Então esses objetos naturais podem apenas ser adornados com um significado e uma glória pessoal por um dom, um dom de uma pessoa, de um homem. Personalidade só pode ser derivada de uma pessoa. Os deuses podem derivar sua cor e sua beleza dos altos esplendores da natureza, mas foi o Homem que as obteve para eles, abstraiu-as de sol e lua e nuvem; sua personalidade eles a obtêm diretamente dele; a sombra ou o brilho de divindade que está sobre tais deuses, eles a recebem por meio dele do mundo invisível, o Sobrenatural. (TOLKIEN, 2020, p.36).

Ao associar tanto as estórias de fadas quanto os mitos tradicionais (como os gregos ou os nórdicos) com o processo de percepção, imaginação, abstração e conceituação, Tolkien propõe três dimensões da produção humana dos mitos, a personalidade humana, os objetos da natureza e o senso do Sobrenatural. É a partir dessa perspectiva que Tolkien critica diretamente uma associação imprevista e deficiente da linguagem (uma doença) entre o nome para um fenômeno natural, uma personalidade e a divindade, base da teoria de Müller, apontando que o processo de integração realizado na imaginação é constituído de três elementos diferentes: objetos da natureza, personalidade humana e sendo do Sobrenatural (maiúscula do autor).

Algo realmente "superior" é ocasionalmente vislumbrado na mitologia: a Divindade, o direito ao poder (enquanto distinto de sua posse), a adoração devida; de fato, a "religião". Andrew Lang disse, e ainda recebe elogios de 
algumas pessoas por tê-lo dito, que mitologia e religião (no sentido estrito dessa palavra) são duas coisas distintas que se tornaram inextricavelmente emaranhadas, embora a mitologia seja, em si mesma, quase desprovida de significância religiosa. Contudo, essas coisas de fato ficaram emaranhadas ou talvez elas tenham sido separadas há muito e tenham, desde então, tateado vagarosamente, através de um labirinto de erro, através da confusão, de volta à refusão. (TOLKIEN, 2020, p.38).

Com efeito, a inteligência humana pode criar o fantástico porque é de sua natureza, porém é necessário que essa subcriação obedeça aos padrões da verdade do mundo primário, que são obtidos pelos sentidos e pelo exercício da inteligência. Essa verdade é antes de tudo moral e metafísica. O motivo pelo qual as estórias de fadas são relegadas ao mundo infantil é a necessidade da crença secundária para que o encantamento de Feéria seja eficaz. Reformulando a suspensão de descrença de Coleridge ${ }^{5}$, Tolkien afirma que a crença naquilo que se vê e ouve (ler) é fundamental e natural a qualquer atividade humana. Segundo o escritor, a teoria dos mitos como alegorias da natureza, proposta por Max Müller, deve ser abandonada, pois a riqueza da fabricação de mitos ultrapassa sua redução a um mecanismo de justaposição de significados.

Os deuses subcriados são compostos, de fato, por elementos da natureza. Eles regem o mar, o céu, o relâmpago, a terra, os animais, a tempestade, até mesmo se confundem em forma com esses elementos. Porém, eles também são justos, generosos, cruéis, iracundos, sábios, traiçoeiros e arrogantes. Tais formas inteligíveis não poderiam ser oriundas de fenômenos naturais, mas só podem ser abstraídas para uma elaboração fantástica a partir de pessoas. Igualmente, o fascínio e o tremor do mistério e do poder trazidos pelos deuses só podem ser explicados pelo mundo invisível, pelo que não conseguimos conceber porque está fora das possibilidades dos nossos sentidos, o Sobrenatural, o mundo invisível com o qual só podemos nos relacionar por metáforas e analogias que buscam nos aproximar da ação da divindade. Assim, natureza, pessoa e divindade compõem a mitologia num processo de subcriação de novas formas na mente, sendo que essa mesma composição tríplice, natureza, homem e Deus, é a configuração das faces das fairy-stories, que convivem com os deuses da alta mitologia tal como os plebeus compartilham o mesmo reino com seus monarcas.

5 Samuel Taylor Coleridge (1772-1834), poeta e filósofo do movimento romântico da Inglaterra (MILBANK, 2007). 
$\mathrm{Na}$ citação acima encontramos a referência a Andrew Lang, conhecido crítico das teorias de Müller, especialmente comentado por Christopher Dawson, citado literalmente por Tolkien. Em Progresso e Religião, Dawson (2012, pp. 134-135) concorda com a afirmação de Lang que as narrativas mitológicas não são o núcleo da religião dos povos antigos, pois tais povos preservam um senso difuso de um Sobrenatural que seria o fundamento de toda existência, uma realidade transcendente aos próprios seres somente relativamente sobrenaturais (deuses, demônios, espíritos, monstros, dríades, elfos). Dawson chega a usar a expressão pélago de substância infinita, usada na Suma Teológica de Tomás de Aquino (ST I, Questão 13, art. 11).

\section{Andrew Lang e Tolkien}

Ao nos aproximarmos de Andrew Lang, é possível detectar essa separação entre mitologia e religião descrita a partir dos estudos do folclore realizados com as metodologias e teorias da antropologia de fins do século XIX.

A tendência irracional, declarada no mito e no ritual, retém e elabora as primevas confusões humanas de pensamento entre homem e besta e deus, coisas animadas e inanimadas. Por um lado, temos quase um reconhecimento da divindade suprema; de outro, ritos e crenças selvagens, compartilhados por australianos e bosquímanos. Não é seguro ou científico originar uma dessas tendências antes da outra; talvez não conheçamos nenhuma raça tão atrasada que não seja influenciada por ambas as formas. Nem é seguro ou científico considerar as práticas mais rudes como corrupções das crenças mais puras. Talvez nunca seja possível rastrearmos os dois riachos até a mesma fonte; provavelmente brotam de fontes distintas na natureza humana. Nós apenas os reconhecemos e contrastamos; as fontes de ambos se perdem na distância, onde a história não pode encontrar nenhum registro da experiência real. (LANG, 1901, p. 57) (tradução própria).

Ao contrário de Müller, não há uma dependência direta entre mitologia, linguagem e divindade. Ao contrário, mitologia e religião são componentes diversos presentes na natureza humana que no decorrer dos séculos tornaramse inextrincavelmente relacionados, mas que podem ser identificados em suas diferenças de qualidade. É essa a diferença entre mitologia e religião que Tolkien resgata de Lang para, ao lado da crítica da gnosiologia (teoria do processo de conhecimento) moderna de Müller, divergir da perspectiva da mitologia (associada à religião) como doença da linguagem. Por outro lado, quando se trata dos contos de fadas (marchen), Lang os diferencia tanto dos 


\section{Diego Klautau}

Carlos Ribeiro Caldas Filho

mitos da natureza quanto dos mitos divinos, ainda que possuam elementos comuns (seres fantásticos, lições morais, cenários incomuns).

As sagas, mitos épicos e marchen não parecem se assemelhar em todos os lugares (como os mitos da natureza), que são as mesmas ideias aplicadas à explicação do mesmo conjunto de fatos naturais. As sagas, épicos e marchen não parecem explicar nada, mas devem ser contadas, em primeira instância, ou para ilustrar e impor uma moral, ou pelo mero prazer da narração imaginativa (LANG, 1901, p.119) (tradução própria).

Ao citar Andrew Lang pela primeira vez no ensaio, Tolkien (2020, p. 37) faz referência à obra Progresso e Religião, do historiador Christopher Dawson (2012, pp. 132-137), que endossa a tese de que mitologia é diferente de religião a partir de estudos etnográficos. Segundo essa teoria, a religião trata da adoração do poder fundante do mundo, enquanto mitologia lida com as explicações dos fenômenos naturais em chave mítico-fantástica. Para Dawson, a essência da religião não é a crença em deuses mitológicos, mas "uma intuição obscura e confusa do ser transcendente - um oceano de energia sobrenatural, pelagus substantiae infinitum et indeterminatum". (DAWSON, 2012, p. 136), uma citação latina direta da Suma Teológica de Tomás de Aquino (2001, p. 311), da questão 13 da Parte I, artigo 02, Os Nomes Divinos, que se relaciona com o Ser Subsistente (Ipsum Esse Subsistens).

Ao voltarmos para Tolkien, encontramos três críticas feitas a Lang concernentes à essa perspectiva da irracionalidade dos contos (estórias) de fadas, especialmente em sua singularidade imaginativa. A primeira é a recusa da atribuição de credulidade como característica das estórias de fadas. $\mathrm{Na}$ introdução da série Fairy Books de Andrew Lang, é dito que o gosto das crianças pelas estórias de fadas representa a era juvenil do homem, cheia de crença e com apetite por maravilhas.

Suspeito que crença e apetite por maravilhas são aqui considerados como idênticos ou proximamente relacionados. Esses conceitos são radicalmente diferentes, embora o apetite por maravilhas não seja diferenciado por uma mente humana em crescimento, de uma vez ou a princípio, de seu apetite geral. Parece razoavelmente claro que Lang está usando crença no seu sentido ordinário: crença de que uma coisa existe ou pode acontecer no mundo real (primário). Se for assim, então temo que as palavras de Lang, despidas

6 A citação latina é da Suma Teológica de Tomás de Aquino (2001, p. 311), da questão 13 da Parte I, artigo 02, Os Nomes Divinos. 
de sentimento, só podem implicar que o contador de contos maravilhosos para crianças deve ou pode se aproveitar ou, de qualquer modo, acaba se aproveitando da credulidade delas, da falta de experiência que torna menos fácil para as crianças distinguir fato de ficção em casos particulares, embora a distinção em si mesma seja fundamental para a mente humana sã e para as estórias de fadas. (TOLKIEN, 2020, p. 47).

Ao recusar a acusação de credulidade como base para o gosto das estórias de fadas, Tolkien diferencia crença do apetite de maravilhas, sendo este o elemento de contemplação próprio da mente humana. É o assombro, a admiração que é base do conhecimento segundo a tradição realista. Por outro lado, desprezar o processo de crença como algo infantil é desconsiderar a importância dessa atitude de assentimento como base da civilização, das instituições sociais e religiosas e da possibilidade de convivência humana. Ao contrário, a diferença entre realidade e fantasia é um dos pré-requisitos para um bom aproveitamento das estórias de fadas.

Ora, eu era uma das crianças a quem Andrew Lang se dirigia - nasci por volta da mesma época que O Fabuloso Livro Verde (1892) —, as crianças para quem ele parecia pensar que as estórias de fadas fossem o equivalente do romance adulto e sobre quem ele disse: "Seu gosto permanece como o gosto de seus ancestrais nus milhares de anos atrás; e elas parecem gostar de contos de fadas mais do que de história, poesia, geografia ou aritmética." Mas sabemos realmente muito sobre esses "ancestrais nus", exceto que eles certamente não estavam nus? Nossas estórias de fadas, por mais velhos que certos elementos nelas possam ser, certamente não são as mesmas que as deles. Contudo, quando se assume que temos estórias de fadas porque eles as tinham, então provavelmente temos história, geografia, poesia e aritmética porque eles gostavam dessas coisas também, até onde eles podiam defini-las e até onde eles já tinham separado os muitos ramos de seu interesse geral em tudo. (TOLKIEN, 2020, p. 50).

A segunda crítica de Tolkien a Lang é contra o primitivismo como pressuposto para o valor das estórias de fadas. Tolkien postula a perspectiva de uma natureza humana comum entre as épocas, tantos dos povos ditos primitivos quanto dos seus contemporâneos, ainda que as mudanças contextuais e a evolução social tragam transformações acidentais. Nesse sentido, não é pela presença de elementos antigos nas estórias de fadas que podemos julgar como primitiva a sua apreciação, pois da mesma forma que os conhecimentos ditos científicos foram derivados da história desses mesmos 
povos ancestrais, refletindo seu desejo natural pelo saber verdadeiro, assim também as estórias de fadas foram preservadas e aprimoradas devido ao seu eco nessa natureza humana.

Não nego que haja uma verdade nas palavras de Andrew Lang (por sentimentais que possam soar): "Aquele que quer entrar no Reino de Feéria deve ter o coração de uma criancinha." Pois essa posse é necessária para toda alta aventura, em reinos menores e muito maiores que Feéria. Mas humildade e inocência - essas coisas "o coração de uma criança" deve significar em tal contexto — não implicam necessariamente um assombro acrítico, nem, de fato, uma ternura acrítica. (TOLKIEN, 2020, p. 53-54).

Por fim, Tolkien rejeita o sentimentalismo atribuído por Lang às estórias de fadas. A ligação entre o coração de criança e o Reino das Fadas possui o sentido negativo, como é atribuído a Lang, de dissociação entre razão e emoção, de ingenuidade tola. Contudo, Tolkien admite que o coração de criança pode ser entendido metáfora de humildade e inocência enquanto virtudes, integrando a razão e a emoção e, portanto, como algo a ser desenvolvido pelo homem maduro com fins à sua excelência filosófica ou como busca de salvação em chave teológica. É nesse sentido positivo da expressão que Tolkien defende a relação entre sermos como crianças para entramos em reinos maiores que os das fadas, como os Evangelhos nos apresentam o acesso ao Reino dos Céus ou Reino de Deus (Mt 18,1-4).

Ao criticar a teoria da mitologia como doença da linguagem, Tolkien recusa tanto a gnosiologia de Max Müller relativa à percepção da natureza e à linguagem quanto sua concepção filológica das relações entre mitologia e religião. Embora associando-se a Andrew Lang para sustentar a diferença entre religião e mitologia, discorda da perspectiva da irracionalidade estrutural das estórias de fadas proposta pelo folclorista. Em suas três críticas a Lang relativas à credulidade, ao primitivismo e ao sentimentalismo, Tolkien aproxima as estórias de fadas aos mitos da natureza e os mitos divinos, apresentando as três faces constituintes das narrativas acerca da terra dos elfos: a personalidade humana, a contemplação da natureza e o senso do Sobrenatural. Para sustentar tal teoria, Tolkien vai buscar fundamentos da tradição filosófica realista, como indicamos no diálogo com Christopher Dawson e Tomás de Aquino, adequado ao contexto europeu católico neotomista de início do século XX. 


\section{Tolkien e a Alegoria.}

A discussão sobre as camadas de sentido de um texto é antiga e muito debatida nas controvérsias sobre escritos sagrados, poemas, narrativas dramáticas e romances. Assim, a metodologia consiste na revisão histórica da alegoria em São Tomás de Aquino (2001) e Umberto Eco (2012) na busca por compreender o termo nas reflexões de Tolkien.

É possível identificar a negação da alegoria, seja como significado oculto ou mensagem secreta, seja como relação a fatos contemporâneos ou a lugares e assuntos determinados (as referências tópicas). A proposta de interpretação que Tolkien oferece é o que ele chama de aplicabilidade, que pode ser usada tanto em ficção como em fatos históricos, na variabilidade de pensamento e experiência dos leitores. Em suma, a alegoria é entendida como método do autor de construir um sentido determinado e fechado da narrativa literal, enquanto a aplicabilidade é um método de interpretação do leitor, que reside na sua liberdade a partir de sua própria experiência. Para Tolkien, essa escolha carregava uma perspectiva moral, entre dominação e liberdade, já nos dando o indício da razão do seu desgosto pela alegoria: reduzia a experiência humana.

Para explicitar nosso recorte, reproduzimos o trecho do prefácio da segunda edição de $O$ Senhor dos Anéis. É preciso lembrar que essa síntese de Tolkien foi escrita para o prefácio de $1965^{7}$, provavelmente no ano anterior, com O Hobbit publicado em 1937 e O Senhor dos Anéis entre 1954 e 1955, ou seja, com décadas de reflexão sobre o assunto

Quanto a qualquer significado oculto ou "mensagem", na intenção do autor estes não existem. O livro não é alegórico e nem se refere a fatos contemporâneos... Outros arranjos poderiam ser criados de acordo com os gostos ou as visões daqueles que gostam de alegorias ou referências tópicas. Mas eu cordialmente desgosto de alegorias em todas as suas manifestações, e sempre foi assim desde que me tornei adulto e perspicaz o suficiente para detectar sua presença. Gosto muito mais de histórias, verdadeiras ou inventadas, com sua aplicabilidade variada ao pensamento e à experiência dos leitores. Acho que muitos confundem "aplicabilidade" com "alegoria"; mas a primeira reside na liberdade do leitor, e a segunda na dominação proposital do autor (TOLKIEN, 2001, p. XIV-XV).

A edição The Lord of The Rings 50th anniversary edition (TOLKIEN, 2004), traz duas notas, uma de Douglas A. Anderson e outra de Wayne G. Hammond e Christina Scull, nas quais são discutidos os detalhes das revisões. 


\section{Diego Klautau}

\section{Carlos Ribeiro Caldas Filho}

Segundo Eco (2012, p. 115-116), ao comentarem as obras de (Pseudo) Dionísio Areopagita (séc. V-VI), os medievais buscavam o simbolismo com um caráter analógico em escala cósmica e sistemática. Seguindo as ideias de Clemente e Orígenes, que afirmavam que Deus como Criador só poderia ser conhecido por via analógica (metáforas ou alegorias), os medievais ampliaram a concepção do transcendente num simbolismo metafísico, buscando as formas que sustentavam a realidade sensível num plano de existência que poderia ser acessado por via dialética, com uma influência neoplatônica. Assim, ao comentar a citação que Huizinga (2010, p. 334) faz de São Paulo (Videmus nunc per speculum in aenigmate, tunc autem facie ad faciem; 1Cor 13, 12), Eco (2010, p.108) interpreta que o que se chama de simbolismo é o raciocínio analógico, afirmando que o curto-circuito lógico, ou a identificação por essência da realidade, é o pensamento analógico ${ }^{8}$.

Seguindo Eco (2010, p. 116-118), a diferença entre o simbolismo dos românticos (como epifania numa mensagem isolada, indecifrável porque reflexo do próprio Real entendido como contradição) e essa linha inaugurada por (Pseudo) Dionísio Areopagita é que a racionalidade existe em certa ordem cósmica relativa ao Uno (do qual a criatura participa) sem contradições. Por isso, a analogia é uma forma de aproximação entre os atributos que podemos inferir de Deus (Bom, Verdadeiro, Belo), mas não como nós atribuímos a nós mesmos, porque muito superiores; daí a necessidade do símbolo. As investigações de Santo Agostinho (séc. IV-V) em sua obra $A$ Trindade vão expor uma ontologia cristã que consagra a analogia como forma de raciocínio primordial para a compreensão das relações entre o homem, o mundo e Deus.

Nesse sentido, são incontornáveis algumas aproximações com São Tomás de Aquino (2002 p. 151-156), a partir de sua a analogia do ser?.

\footnotetext{
8 "Em todo caso, o curto-circuito ou a identificação por essência baseiam-se em uma relação de proporção (que é a relação de analogia em seu nível menos metafísico: a rosa está para os espinhos assim como o mártir para seus perseguidores). Sem dúvida a rosa é diferente do mártir; mas o prazer que resulta do descobrimento de uma bela metáfora (e a alegoria não é senão uma cadeia de metáforas codificadas e extraídas uma da outra) deve-se justamente àquilo que o Pseudo Dionísio (De coelesti hier. II) já indicava como incongruidade do símbolo em relação à coisa simbolizada. Se não existisse incongruidade, mas só identidade, não existiria relação proporcional (x não estaria para y como y está para z)." (ECO, 2010, p. 108-109).

9 "Com este termo indica-se a relação de participação que existe entre o ser infinito de Deus criador e o ser finito dos entes criados: trata-se de uma relação analógica, isto é, de semelhança, intermediária entre a univocidade e a equivocidade, o que significa nem completamente idêntico nem completamente diferente. O ser é o conceito analógico por excelência, enquanto se predica de toda realidade, porém seu modo varia essencialmente de um gênero para o outro". (REALE e ANTISERI, 2009, p. 220).
} 
Seguindo no artigo 09 da $1^{\text {a }}$ questão da Parte 1, a Suma Teológica afirma que é natural ao homem partir do que é sensível para o inteligível, legitimando a metáfora nas Sagradas Escrituras, principalmente por sua abrangência para pessoas em vários níveis de conhecimento, das mais simples às mais letradas. $\mathrm{Na}$ primeira resposta, afirma que apesar da poesia (lugar por excelência do uso da metáfora) ser uma ínfima doutrina (a última dentre as ciências), ela de fato provoca prazer ao homem, enquanto a sagrada doutrina usa as metáforas por necessidade da razão na aproximação do desconhecido.

Prosseguindo na Parte 01, questão 01, o artigo 10 trata dos vários sentidos das Escrituras Sagradas, recuperando a teologia dos quatro sentidos (literal, alegórico, moral e anagógico). Inicialmente, Tomás vai desenvolver seu conceito de significação ${ }^{10}$, ressaltando que Deus pode significar algo tanto com palavras quanto com as coisas (eventos, corpos, imagens), sendo que, em relação aos textos, a primeira forma é a literal ou histórica, e a segunda quando as coisas que são significadas nas palavras também significam algo diferente na realidade (revelações, vontade de Deus, Providência, castigos).

O sentido espiritual se divide em três: o alegórico se refere diretamente à interpretação da lei antiga pela nova, com os princípios do Novo Testamento sendo a chave para a leitura do Antigo, sendo Cristo a figura que é espelhada nos profetas; o moral são os atos de Cristo que devemos imitar; e por fim, o anagógico é o prenúncio da comunhão com Deus no fim dos tempos. Assim, Tomás insiste que todos estes sentidos estão fundados no literal, não existindo contradição ou oposição entre eles. Da mesma forma, insere a analogia no sentido literal, se referindo ao método comparativo de trechos diferentes da Escritura, buscando suas semelhanças e diferenças.

Por fim, é ressaltado o sentido parabólico da Escritura, afirmando que ele pertence ao sentido literal, uma vez que a significação literal de um texto contém o sentido próprio e o sentido figurado. Tomás dá o exemplo da expressão "braço de Deus" na Escritura, cujo sentido literal não significa um membro corporal de Deus, mas sim seu poder de operar, preservando a veracidade da Escritura. É nessa dimensão figurada, que Tomás chama de parabólica (podemos relacionar com as parábolas de Cristo), que está o

10 Segundo o verbete da Suma Teológica consultada, escrito por Marie-Joseph Nicolas (2002, p. 98) significação "É sinal toda coisa que faz conhecer uma outra, seja por uma relação natural de uma a outra (relação de causalidade, de semelhança, de analogia), seja por uma relação convencional (linguagem), seja instituída (ritos), seja por um complexo dessas três coisas. A significação é a relação de um sinal com aquilo que ele faz conhecer e evoca ou o poder que possui o sinal de fazer conhecer isto ou aquilo." 


\section{Diego Klautau \\ Carlos Ribeiro Caldas Filho}

sentido metafórico derivado do sentido literal, buscando uma significação plena para além dos signos descritos, em direção às realidades (humanas e divinas) às quais eles se referem por analogia e, nesse sentido, exigindo uma aproximação simbólica.

Tolkien concorda com os medievalistas que tanto símbolo quanto alegoria podem se referir ao mesmo raciocínio analógico em modos diferentes, e nos permite inferir que a interpretação simbólica é aprovada por ele, numa alusão à passagem bíblica do livro do Gênesis, onde Deus vê que sua criação é boa (Gn 1, 4-31). É fundamental aqui resgatar o sentido parabólico de São Tomás de Aquino, que está fundado na literalidade, mas que se refere a um raciocínio analógico via metáfora, pois como Deus pode criar falando, se não tem boca? Ou como pode ver, se não tem olhos? Somente a analogia entre a possibilidade de criação dos sons e da linguagem pelos homens e a onipotência da Criação de tudo o que existe por Deus pode nos aproximar desse sentido da narrativa, assim como a contemplação da Criação pelos homens nos aproxima da admiração infinita (poderia se dizer amor) que Deus tem pelo que criou.

A validade da leitura alegórica para os textos sagrados se cumpre porque a revelação cristã, por meio da tradição apostólica, afirma que a analogia fechada entre antigo testamento e novo testamento é certa e infalível. É possível, assim, afirmar que tudo que está no antigo testamento encontra a culminância de seu significado a partir do novo testamento, sendo perfeitamente ajustada a alegoria entre ambos. Por outro lado, em termos de literatura mundana - não sagrada - seria temerário impor uma alegoria definitiva com presunção de se relacionar com a verdade, pois o autor individual não possui a mesma inspiração divina do escritor dos textos sagrados. Por isso, a alegoria como ferramenta de criação e interpretação, ainda que válida para textos sagrados, não possui a mesma força e legitimidade para textos profanos, literários no caso da fantasia. Para esse caso, é o sentido parabólico proposto por Tomás de Aquino, derivado meramente do sentido literal, mas que é fecundo para a analogia aberta, que ampara o exercício da razão natural para a reflexão mítica e simbólica em direção à verdade, tanto em seus aspectos morais quanto metafísicos.

Em suma, Tolkien aceita o símbolo como interpretação (aplicabilidade), desde que associado a uma ontologia imaginária derivada de sua própria literatura, daí sua insistência em publicar O Silmarillion juntamente com O Senhor dos Anéis. Dentro dessa ontologia imaginária existem de fato 
algumas ideias religiosas. Elas, contudo, não são alegóricas; ou seja, buscam se sustentar dentro da própria obra literária (daí sua imensidão), que não pretende ser uma pregação ou um didatismo moral, mas um objeto de admiração e contemplação de atos humanos e da natureza em ato. Nesse sentido, a perspectiva da aplicabilidade entendida como significação, ou seja, a relação entre um sinal ou imagem e uma outra realidade (material ou espiritual), é coerente desde que se conceba os universais e não uma correspondência particular. Com efeito, a afirmação de que uma narrativa poética pode expressar um sentido parabólico é explicitamente referendada na carta (215) de abril de 1959, onde Tolkien (TOLKIEN; CARPENTER, 2006, p. 284) explica que seu "comentário sobre o mundo" é mais bem exposto em forma literária, ainda que não seja uma alegoria, pois "a maioria dos leitores parece confundi-la com significação ou aplicabilidade".

A alegoria, segundo Tolkien, não permite a liberdade do leitor porque pode construir um sistema que escraviza o imaginário. Mais ainda, ao ter a pretensão de um raciocínio fechado, flerta com a tentação do conhecimento absoluto, roubando a onisciência (e a onipotência, no caso da fabricação de mitos) divina. Ao decifrar o enigma e descobrir o segredo da alegoria, se esgota todo espaço para descoberta de novos sentidos e do maravilhar-se (thaumaston) numa obra literária. De forma contrária, é na incongruência, na estranheza, na fecunda falta de explicação plena, no jogo entre semelhanças e diferenças dos quatro termos da analogia que está a satisfação da interpretação ${ }^{11}$ simbólica (no sentido tomista de metáfora e de parábola, que pressupõe o sentido literal e se desenvolve a partir dele). Tal interpretação possui dupla dimensão: afetiva porque imaginária, e efetiva porque atualiza as formas inteligíveis a serem admiradas no mito construído, tal como se admira uma cena na pintura ou uma postura na escultura.

No texto, Tolkien apresenta o conceito das estórias de fadas em chave mitopoética (ou mitopeica), ${ }^{12}$ como narrativas sobre Faerie, mundo

\footnotetext{
11 "Além disso, lembra Dionísio, é exatamente da incongruidade que nasce o esforço deleitoso da interpretação. É bom que as coisas divinas sejam indicadas por símbolos muito diferentes, como leão, urso, pantera, porque é justamente a estranheza do símbolo que o torna palpável e estimulante para o intérprete (De coelesti hier. II). (ECO, 2010, p. 109).

12 Mythopoeia é o título de um poema de Tolkien de aproximadamente 1930 e publicado pela primeira vez em 1964. Trata-se de uma discussão, entre Philomytus e Misomythus, sobre a validade de estudar os mitos antigos e reivindica o direito da humanidade de não apenas estudá-los seriamente como também de produzi-los de forma independente, não apenas como narrativas já acontecidas, mas como direito humano de narrar sobre o que está além do homem, usando imagens inspiradas, criadas ou inventadas que não estão presentes na realidade cotidiana.
} 
onde acontecem as estórias. É a narração de espaço e tempo, personagens e situações que por estarem livres da contingência material, espacial e temporal podem avançar imaginariamente na investigação das verdades transcendentes. Assim, o ofício do escritor assume um compromisso com a verdade e com o mundo real. Esse mundo real torna-se então o mundo primário, ou a Criação de Deus, que é o autor supremo e absoluto, enquanto o homem criado à imagem e semelhança de um criador é subcriador, ou seja, a fabricador de um mundo secundário onde, através da fantasia, pode libertar-se das ilusões e limitações do mundo primário que o impedem de investigar e vislumbrar as maravilhas da verdade.

Essa capacidade de subcriar e dessa forma adentrar em Faerie, no mundo secundário, é mais perceptível nas crianças. Por isso, mantevese a ideia, que Tolkien abertamente rejeita, de que estórias de fada são fundamentalmente infantis. Pior ainda, a infantilização das estórias de fadas limita sua própria natureza, que é adentrar em todo o horror e decadência, regozijo e esperança, que a verdade revela sobre a condição humana e sobre a natureza do cosmos e do Transcendente. Dessa forma, a subcriação se torna necessária como investigação acerca dos mistérios humanos, tanto para crianças como para adultos. Aí se encontra na reflexão sobre mitologia. Com efeito, Tolkien afirma que a magia de Faerie não é um fim em si mesmo e que sua virtude está nas operações subcriativas, cuja principal delas é a satisfação dos desejos humanos primordiais de inspecionar as profundezas do espaço e do tempo e de comunhão com todas as coisas vivas.

Essa antropologia filosófica de base em Tolkien (2020, p. 36-39) é fundamental para a compreensão de seus ensaios, de suas análises e mesmo de sua mitopeia (mythopoeia). O homem possui esse desejo de conhecer (confins do tempo e do espaço) e de comunhão (com todas as coisas vivas) enquanto estrutura irrevogável. Ainda que nunca consiga plenamente todas as respostas e todos os desejos (desproporção estrutural), esse impulso que move razão, emoção e imaginação está na base da consciência, como uma esperança que está na própria substância da humanidade. É justamente dessa antropologia que deriva toda a teoria literária de Tolkien.

Com efeito, Tolkien discorda tanto de Andrew Lang, que considerava a mitologia uma decadência da religião, quanto de Max Müller, que desenvolveu uma ciência da linguagem para determinar a transformação do sentimento do sublime em nome, e daí a personificação enquanto sagrado (a passagem do nomina para o numina). Müller atribuía essa passagem a certa patologia da 
linguagem, enquanto Tolkien afirma que o exercício de confecção de mitos para a experiência religiosa é natural ao pensamento humano, e, assim como criou a comunicação de experiências, também deu origem às estórias de fadas.

Essa mesma é a origem do conhecimento científico, de manipulação da realidade (ou a magia). Porque a inteligência humana abstrata não pode atuar sobre os dados dos sentidos, ela apenas atua sobre as imagens da memória (generalização e abstração), de onde extrai o conceito universal. Daí a expressão em palavras ou números do conteúdo constante e igual entre várias imagens do mesmo tipo. Essa capacidade permite a qualificação das coisas na realidade; o processo mental que consolida a operação do adjetivo é o "feitiço ou encantamento" mais poderoso de Feéria. Essa operação de qualificação como o processo de criação de imagens (como na mitologia) também é uma forma de possibilidade de alteração da realidade. Da mesma forma que a mente concebe "leve", "pesado", "cinza", "amarelo", "parado", "veloz", também concebe formas de manipulação das coisas (tanto na subcriação literária quanto na constituição da realidade) para alterar suas propriedades e dar novos adjetivos às coisas na própria realidade. Daí os processos de transformar o pesado em leve, o terrestre em voador, o chumbo em ouro. Obviamente que essa faculdade da mente humana é como qualquer outra faculdade, e pode de fato ficar adoentada, ser utilizada não para construir ou transformar, mas para destruir e degradar.

Embora sem citar literalmente, Tolkien segue as concepções de Aristóteles e Tomás de Aquino (ANDERSON \& FLIEGER, 2014), (MCINTOSH, 2017), (TESTI, 2018) e entende que é na imaginação e na memória que se opera a transição do particular para o universal, conservando a figura da forma individual. A forma inteligível das coisas (grama, sol, chumbo) permite captar a espécie à qual pertence e que está na própria coisa singular. Porém, não se pode ver a forma inteligível; daí a necessidade de generalização e abstração e, portanto, a discriminação das espécies (grama e verde). Porém, a imaginação realiza uma mediação entre indivíduo e espécie, visualizando o singular e concebendo o universal.

No caso das estórias de fadas (como na mitologia), é necessário que se pratique uma crença nesse mundo criado, nessa subcriação de imagens fabricadas a partir do mundo primário, porque somente assim é possível iniciar uma reflexão e investigação via imaginação sobre a verdade e o inteligível. Entendendo a si mesmo como escritor e subcriador, adepto de uma atividade humana tão primordial quanto o pensar, se comunicar e contemplar, 


\section{Diego Klautau}

\section{Carlos Ribeiro Caldas Filho}

Tolkien (2020, p. 49-50) expressa sua preocupação com as virtudes e valores que percebia escassos em seu tempo. Dessa forma, embora haja de fato diferenças cruciais entre religião, mitologia e estórias de fadas, Tolkien afirmava que todas elas estavam emaranhadas. $\mathrm{Na}$ verdade, fazia alusão a uma espécie de "sopa narrativa", na qual diversos elementos estavam presentes, religiosos, mitológicos e mesmo fantásticos, como as estórias de fadas.

As estórias de fadas trazem a reflexão de Feéria, em seus níveis de questionamento e de aprofundamento sobre a realidade e sobre a experiência humana em direção ao desconhecido e imprevisível. Segundo o próprio Tolkien, a natureza de Feéria é indescritível, porém não é imperceptível e nenhuma análise poderá revelar seus segredos. Logo, as estórias de fadas possuem uma tradição própria, que remonta a pessoas, lugares e criaturas que podem ser encontradas em diversos tempos e lugares. Os elementos das estórias de fadas estariam misturados no grande Caldeirão de Estórias, no qual os poetas e escritores fariam suas sopas, as narrativas que são construídas durante o tempo e o espaço. Os anéis de poder, os corações escondidos, o cetro, a estrela, o cristal, a espada, o dragão, o cavaleiro, o mago, os monstros são, todos, elementos constitutivos das estórias de fadas.

Após essa definição das estórias de fadas como uma narrativa sobre Feéria, um mundo secundário, fabricado por imagens que estabelecem contemplação do homem da criação na qual está inserido, Tolkien apresenta suas origens na mitologia e na própria natureza da linguagem, especialmente quando expressa verdades inteligíveis e que comunicam experiências religiosas. É justamente nesse ponto que Tolkien responde sua segunda pergunta: qual a origem das estórias de fadas? Fazendo uma comparação com a filologia, existem três metodologias de pesquisa em relação aos elementos que compõem as estórias de fadas, seja através da evolução independente, da difusão ou da herança. Para Tolkien (2020, p. 33-34), o elemento mais difícil de tratar é a evolução independente, pois trata da invenção. A busca pela difusão, propagação no espaço, ou pela herança, propagação no tempo, apenas desloca a questão da origem para um debate mais complexo e com mais elementos.

Assim, Tolkien afirma a incapacidade do método científico analítico em desvendar as origens de Feéria (da mesma forma que as do mito), chegando ao máximo a dissecar seus elementos e fazer certa arqueologia dos personagens, objetos e lugares comuns às estórias de fadas. Porém, embora pesquisando carnes, legumes e ingredientes de uma sopa, o que mais importa é como ela é servida e se realmente é saborosa e nutritiva. Daí a preocupação 
de Tolkien com as funções e utilidades das estórias de fadas. Para Tolkien (2020, p.38), as estórias de fadas são essencialmente sobre a Natureza e isso corrobora a ideia da sua preocupação sobre a condição moderna e da exploração da natureza pela ciência e pelo capital. Também as estórias de fadas têm seus elementos de reflexão sobre o ser humano, enquanto condição e destino, e sobre o mistério, centro da religião. Tanto o espelho da condição do homem quanto a dimensão mística podem estar presentes nas estórias de fadas, porém seu fundamento é a mágica, a representação e o reconhecimento da Natureza.

Nesse sentido, a face essencial de Faërie é a natureza porque se trata sempre do maravilhamento diante das possibilidades do mundo natural, quanto conjunto dos entes. A existência e seus elementos são reorganizados mitopeicamente (relativo à mythopoeia, ao artesanato de mitos), com o objetivo de transformar (alteração da forma substancial nas subcriações literárias) os entes para que possam ser admirados a partir do estranhamento e da indagação, o fundamento da contemplação intelectual ${ }^{13}$. Daí as fadas sempre compostas de elementos combinatórios do mundo primário, a realidade, como pessoas e pássaros (fadas aladas), ou homens e animais (centauros, minotauros) ou mesmo fusão de predadores de outras espécies com a inteligência humana (lagartos e águias como dragões), ou ainda, no caso de Tolkien, várias modalidades de ser humano, mais próximos de elementos minerais, como anãos ligados à pedra, elfos ligados ao ar ou magos ligados ao fogo.

A função, utilidade, das estórias de fadas é justamente ser um novo olhar para o mundo. Essas estórias, por tratarem de um lugar, de um encontro entre os homens e algo que está além deles, porém presente em seu desejo, são um lugar de novidade, de assombro e de surpresa. São o espaço em que o mistério se apresenta com novas imagens, em que os dramas humanos são revisitados, reatualizados e reconhecidos. Eis Feéria, que novamente se reencanta ${ }^{14}$ com o cotidiano da natureza. A limitação da estória como objeto

13 A expressão Philomythus está no Livro I da Metafísica de Aristóteles e aparece ao lado do Philosophos como ambos sendo iguais na admiração das maravilhas (assombro, indagação, espanto) da realidade. A expressão maravilhoso (thaumaston) é repetida na Poética (1452a, 1456a, 1460a) aristotélica, nos capítulos IX, XVIII, XXIV. No ensaio, Tolkien usa as expressões wonder e marvel com o mesmo sentido clássico do grego thaumaston.

14 Essa visão de reencantamento pode ser uma resposta a um diagnóstico do teórico alemão de uma geração anterior a Tolkien, Max Weber (1864-1920), que aponta uma característica da modernidade um desencantamento do mundo, entendido como a retirada do pensamento religioso como forma de ver a realidade (FIROLAMO, PRANDI, 1999). 


\section{Diego Klautan}

Carlos Ribeiro Caldas Filho

determinado analiticamente (como em Lang ou Müller) retira a potência da inteligência para novas inspirações. Com efeito, Tolkien entende que a estória (a boa estória) é um instrumento interpretativo da realidade e de condensação de possibilidades simbólicas de outras percepções que o indivíduo venha a ter no decorrer de suas releituras e experiências de vida.

Esse novo olhar promovido pelas estórias de fadas em relação à realidade é o fundamento de sua existência. O que preserva as estórias de fadas são suas virtudes e valores, presentes em si e espalhadas e difundidas em todos os que se aventuram em Feéria. Daí a associação das estórias de fadas com as crianças. Embora Tolkien (2020, p. 44-56) discorde dessa associação imediata, diz que o fundamento de tal associação é a capacidade de as crianças acreditarem em coisas novas, abrirem a mente ao conhecimento, capacidade esta que existe também nos adultos, porém de uma forma mais prejudicada, principalmente nos domínios das máquinas, do cotidiano amedrontador e acachapante e do materialismo.

Essa capacidade de crença está expressa porque as estórias de fadas não estão preocupadas somente com a possibilidade material (daí o irreal, o sobrenatural e o sobre-humano), mas também têm o desejo natural de coisas esplêndidas e transcendentes. Em termos de possibilidades, são as virtudes e valores presentes nas coisas esplêndidas que são trazidas pelas estórias de fadas através da fantasia, que é a capacidade imaginativa de formar imagens mentais que não estão presentes, assim como estruturas metafísicas de funcionamento do cosmos e do Transcendente.

Assim, são três as utilidades das estórias de fada apresentadas por Tolkien (2020, p. 64-77): o escape, transporte para fora do mundo em que estamos aprisionados na matéria; a recuperação, elemento que retoma a natureza de comunhão com as coisas vivas e de integralidade humana; e a consolação, que permite ao homem esperar algo além de sua visão limitada pela própria condição humana. Tais funções das estórias de fadas se reúnem em um conceito central de Tolkien: a subcriação. A principal forma das estórias de fadas atingirem seus objetivos, o encontro com Feéria, é a criação de um mundo fantástico. Cada subcriador se utiliza dos elementos do Caldeirão de Estórias, e serve sua sopa com determinados elementos já existentes. Porém, é graças à atividade artística do subcriador que se consegue a medida para que os meios das estórias de fadas consigam produzir frutos. A subcriação é feita quando se consegue produzir uma crença secundária, em que o leitor se permitir acreditar em algo verossímil, coerente, mesmo 
que num ambiente de criaturas sobre-humanas, num ambiente sobrenatural, com divindades e seres muito além da realidade material.

Essa correspondência com a Criação, o mundo no qual vivemos, passa pela realidade da divindade criadora. São as virtudes e valores promovidos pela razão e pela revelação que estabelecem a correspondência em termos da natureza humana, pois Deus nos indica como agir, além de suas manifestações, corretamente através da razão e da contemplação da Criação. Em suma, pode até existir um mundo com o sol verde, com árvores amarelas, porém deve obedecer a um parâmetro que permita uma explicação de que Deus criou o sol verde para expressar a gratidão da grama, e as árvores amarelas para mostrar a proteção do fogo quando usado para aquecer os homens. Assim, como na religião do mundo primário, na Criação a arte subcriativa demonstra o cuidado de Deus com a natureza e com os homens, e nisso existe a lógica religiosa real no mundo primário.

Da mesma forma, homens compostos de ferro, num mundo subcriado, devem seguir as virtudes da mesma forma que os homens de carne e osso no mundo primário, pois a honra e a coragem são importantes tanto no mundo primário, na Criação, quanto nos mundos secundários. Se, ao contrário, os homens de lama forem traidores e mentirosos no mundo secundário, também a traição e mentira estão presentes no mundo primário. Somente assim será possível estabelecer uma ligação entre a natureza dos homens e a arte subcriativa. Para Tolkien (2020, p. 64), o elemento fantástico é apenas um método para barrar os condicionamentos impostos à humanidade em sua prisão. Tolkien responde às críticas de escapismo afirmando que é errado confundir o respiro do prisioneiro com a fuga do covarde. Mesmo em sua condição de pecado, o homem sabe que existe algo maior que ele, que o sustenta e o sacia, o tranquiliza e o redime. Na arte da subcriação, tão antiga quanto a mitologia e a religião, porém um pouco mais familiar, faz-se um exercício de imaginação que se eleva à contemplação do mistério do sobrenatural.

Definindo as três funções das estórias de fadas, Recovery, Escape, Consolation, e preocupando-se com os seus usos, Tolkien (2020, p.65-76) busca essa experiência da unidade primordial da religião, da mitologia e das estórias de fadas. Sendo um instrumento de transmissão da verdade, da contemplação da educação moral, as estórias de fadas são importantes enquanto arte, atividade necessária ao homem enquanto criatura subcriador. Ao se aventurar para além dos mitos conhecidos, das estórias contadas às 


\section{Diego Klautau}

\section{Carlos Ribeiro Caldas Filho}

gerações, ao estudo da mitologia comparada e já estabelecida, Tolkien propõe a subcriação como forma de reviver, rememorar com algo inédito as mesmas verdades presentes no mundo primário.

Para tal, propõe uma divisão nos termos existentes da relação com o encantamento em seu ofício. O termo Magia é usado de forma instável no ensaio, com o próprio Tolkien (2014, p.32) mudando seu uso no decorrer do texto. Por um lado, o termo é entendido simplesmente como a capacidade humana de alteração da realidade, sentido que Tolkien (2014, p. 63) equivale a Arte $\left(\right.$ technế ${ }^{15}$, conceito próximo à tecnologia moderna, moralmente neutra. Por outro lado, a palavra é usada também como manipulação da vontade de homens, tal qual a goeteia platônica, utilizada no capítulo III da República (413c), entendida como encantamento para testar os jovens em treinamento para serem os guardiões da cidade. Por fim, Tolkien (2014, p. 64) se refere à Magia como encantamento élfico enquanto arte (poiesis) mitopeica em si mesma, a própria Faërie, cuja finalidade é de maravilhamento (thaumaston) da natureza a partir de suas novas fabulações subcriativas.

Dessa forma, a magia em Tolkien é entendida primeiramente como o conhecimento para a alteração do mundo primário, e aqui ele faz a aproximação da máquina e do tecnicismo, como entendemos o reducionismo da ciência moderna que ele mesmo criticava. Essa magia é baseada no desejo de poder, de controle e de posse, natural da condição de pecado. Todavia, existe a arte (magia) propriamente dita, ou seja, um processo humano de criação, ou subcriação, através de um meio artístico (literário, pintura, escultura) ou mesmo científico, que produz o caminho (o método) para a crença secundária. E por fim o encantamento mágico, o ofício da subcriação propriamente dito, a ação de produzir o mundo secundário em consonância com contemplação do receptor. Para além de fazer certa arqueologia mitológica, ou filológica, ou das estórias de fadas, Tolkien propõe o fantástico como centro da subcriação. Ao aceitar algo fora do padrão imposto por uma época de racionalismo, de exigência severa com os ditames da simples razão, Tolkien exaspera e irrompe a fantasia como lugar de refrigério, de repouso, de desafio, de dilemas e, antes de tudo, de verdade.

15 Essa perspectiva da Arte como techné e poiesis na esteira da tradição aristotélica-tomista em Tolkien é endossada por Alison Milbank (2007, pp. 21, 23, 142-143, 166-168), especialmente na relação que a autora traça entre os fundamentos filosóficos de Jacques Maritain em sua obra Art and Scholasticism e os pressupostos teóricos de Tolkien, enfatizando essa transição, própria dos católicos europeus da primeira metade do século XX, da leitura romântica da natureza para uma perspectiva (neo)tomista. 
Assim, Tolkien (2020, p. 63-64) afirma que não só a fantasia é uma atividade natural do homem quanto sua prática pode favorecer a razão e, antes de tudo, é estimulada por ela. Propõe a fantasia da mitopeia como uma atividade racional, criativa e sincera em busca da consonância entre fé e razão. Porém, Tolkien também estava ciente das dificuldades e perigos que um mundo como Faerie poderia oferecer. O estudo da fantasia deve ser realizado racionalmente com seriedade, na investigação da filosofia moral. A queda humana ainda é uma realidade terrível, e tudo pode ser deformado na mórbida ilusão, e da arte de libertação, transformar-se em mais uma escravidão idolátrica humana.

\section{Conclusão}

A crítica feita por Tolkien a Max Müller e Andrew Lang se fundamenta em uma diferença de concepção antropológica e, portanto, gnosiológica. As relações entre mente, linguagem e percepção da realidade subjacentes na teoria do autor de $O$ Senhor dos Anéis resgatam elementos da filosofia perene, da tradição realista estabelecida pela leitura escolástica da filosofia de Platão e Aristóteles, mediada pela patrística, como em Santo Agostinho, e sintetizadas nas sumas medievais, como a de Tomás de Aquino. A questão da alegoria, conforme concebida por Müller e Lang em contraste com a proposta de Tolkien fundada na filosofia perene, evidencia essa disparidade.

Como exemplo final dessa perspectiva, é possível notar que, na dimensão fantástica da consolação, do escape e da recuperação das estórias de fadas, existe um desdobramento fundamental no pensamento religioso de Tolkien, a eucatástrofe. De evidente inspiração aristotélica, eucatástrofe significa a boa catástrofe, a virada que permite que os valores e virtudes que estão no mundo primário prevaleçam no mundo secundário. A subcriação na medida correta acontece quanto mais for verossímil a eucatástrofe, e isto significa o máximo possível de verdade (inclusive catastrófica) que existe na realidade na qual o homem está. O final feliz característico das estórias de fadas não é algo romântico, ingênuo ou incoerente, mas parte integrante da vida e da experiência humana.

Existe de fato a catástrofe e a tragédia, experimentadas através das perdas, confusão, mortes e sofrimento, e muitas vezes essa eucatástrofe não é exatamente como gostaríamos que ela fosse. Existem mudanças e muitas vezes as coisas seguem rumos nunca imaginados e de fato indesejados, a tyche (fortuna ou destino incerto) trágica, com seus daimons (espíritos e possessões), 


\section{Diego Klautau}

Carlos Ribeiro Caldas Filho

a hamartia (erro crítico), a ate (cegueira) e a hybris (orgulho) (JAEGER, 2003). $\mathrm{Na}$ subcriação deve haver uma plausibilidade, uma tensão que também existe no mundo primário, estabelecendo, assim, a ligação entre o mundo primário e o secundário. Assim como na Criação muitas vezes pensamos que os valores e virtudes não são reais, devemos mantê-los para conseguirmos entender quão válidas são também no mundo secundário. Para afirmar esse conceito, Tolkien (2020, p. 78-79) apresenta a maior estória de fadas que conhece: os Evangelhos com a narrativa da vida, ensinamentos, paixão, morte e ressurreição de Jesus Cristo.

A ideia da eucatástrofe se coloca ao lado da ressurreição. A diferença entre estórias de fadas, história e lenda é abolida, assim como a separação entre Deus e o homem é superada, e o véu da presença de Deus na história é tirado. O Evangelho é a vida de Jesus Cristo, que se inicia na história enquanto homem, natureza e mistério. Porém, é justamente a arrebentação desses limites que orienta a fé cristã.

O mundo natural é vencido pelos milagres, curas e assombros (thaumaston) que Jesus Cristo realiza, e finalmente a Glória cristã é a alegria do encontro com um Deus que é Pai, que ressuscita Jesus Cristo como salvação de toda a humanidade. No mundo primário, revela-se a grande eucatástrofe; nesse sentido, Feéria é um vislumbre do Reino de Deus no mundo. Como mundo secundário, reflete o mundo primário, lugar da revelação, uma nostalgia do Paraíso perdido no relato bíblico e alegria da certeza da vitória sobre a morte. Feéria é esse lugar de reencontro do homem com os anjos (com os elfos, hobbits, anões, ents e magos) sob a guarda amorosa da Trindade.

Em certo sentido, o drama evangélico com a ressurreição é que legitima e redime todas as outras estórias de fadas. Por isso, é o Evangelho que é o Fogo que alimenta o Caldeirão de Estórias de onde surgem todas as porções mitopoéticas da Sopa que surge no processo subcriativo, que rasga a diferença entre mundo primário e mundo secundário, que justifica e redime todos os subcriadores de mitos e estórias de fadas de todas as épocas e de todos os lugares. Ainda que o Evangelho seja imensamente superior em verdade e relevância, o grande não despreza o pequeno. As modestas investigações mitopoéticas que possam ser feitas não são invalidadas ou ridicularizadas pela imensidão evangélica. Ao homem ainda é preservado o direito à eucatástrofe e ao final feliz.

A importância da imaginação para a Teologia é indicada na divisão trinitária apontada por Santo Agostinho nos capítulos IX e X do livro 
A Trindade, na analogia entre a estrutura tríplice da mente humana com a Santíssima Trindade cristã. Para o Bispo de Hipona, existe a Memória (imaginação) como origem do nosso pensamento por meio da preservação das imagens percebidas pelos dados dos sentidos; a Inteligência que, a partir dessas imagens, opera a formação do conceito e é responsável pela percepção do inteligível (imaterial) e o expressa em linguagem humana; e a Vontade, como ação motivada pelo amor na realização das práticas humanas e na concentração, meditação e esforço na compreensão da realidade.

Da mesma forma, a origem da Criação é a Mente Divina, Deus Pai, enquanto a estrutura lógica da Criação é o próprio Verbo, Logos, o Cristo como Sabedoria da realidade, e o Espírito Santo que manifesta a Vontade Divina, inclusive na operação da efetividade da Criação. Ora, é possível inferir nessa analogia que a Memória (imaginação), tanto em nós quanto na Trindade, não tem somente uma função preservativa, de retenção dos dados, mas sobretudo gerativa, com a proposição de novas formas a partir da originalidade (fantasia), seja do próprio Deus Pai na Criação em si mesma, ou na mente humana, como a origem das formas inéditas subcriadas pelo artista com contribuição para a beleza do mundo.

Esse direito não é o direito ao escapismo e à fuga, à ilusão e ao autoengano, mas o direito à fé que possibilita um escape da vida mundana e ao vale de lágrimas trágico que é a peregrinação do homem em sua vida; o direito à recuperação do deserto estéril do pecado, que se realiza com a comunhão com as coisas vivas e criadas (contemplação) e com os poucos e íntimos que nos trazem a caridade recíproca como presença de Jesus Cristo; e a consolação, que sacia esse desejo de infinito, essa promessa de realização diante do mistério e da desproporção estrutural da condição humana, essa esperança que já é em si uma realidade.

\section{Referências}

ANDERSON, Douglas A.; FLIEGER, Verlyn (ed.). Tolkien on fairy-stories. London: HarperCollins, 2014.

AgOstinho, Santo, Bispo de Hipona. A trindade. Tradução de Frei Augustino Belmonte. São Paulo: Paulus, 2005.

ARISTÓTELES. Poética. Tradução e notas SOUSA, Eudoro de. Lisboa: Imprensa Nacional; Casa da Moeda, 1986.

BÍBLIA DE JERUSALÉM. São Paulo: Paulus, 2002.

CROATTO, José Severino. As linguagens da experiência religiosa: uma introdução à fenomenologia da religião. São Paulo: Paulinas, 2001. 
Carlos Ribeiro Caldas Filho

DAWSON, Christopher. Progresso e religião. Tradução de Fábio Faria. São Paulo: É Realizações, 2012.

ECO, Umberto. Arte e beleza na estética medieval. Rio de Janeiro: Record, 2010.

FIROLAMO, Giovanni; PRANDI, Carlo. As ciências das religiões. São Paulo: Paulus, 1999. HUIZINGA, Johan. O Outono da Idade Média. São Paulo: Cosac Naify, 2010.

JAEGER, Werner. Paideia: a formação do homem grego. Tradução de Arthur M. Parreira. São Paulo: Martins Fontes, 2003.

LANG, Andrew. Myth, Ritual and Religion. Vol. II. London, New York and Bombay: Longmans, Green, And Co. (1887),1901

MANNI, Franco; SHIPPEY, Tom. Tolkien between Philosophy and Philology. In: Tolkien and Philsophy. ARDUINI, Roberto; Claudio A. Testi. Walking Tree Publishers, Zurich and Jena, 2014. p. 21-71.

MCINTOSH, Jonathan. The flame imperishable: Tolkien, St. Thomas and the metaphysics of Faërie. Kettering, OH: Angelico Press, 2017.

MILBANK, Alison. Tolkien and chesterton as theologians. New York: T\&T Clark, 2007.

MÜLLER, Max. Lectures on the Science of Language vol. I. London: Longmans, Green and Co., (1861) 1885

NICOLAS, Marie-Joseph. O vocabulário da suma teológica. In: TOMÁS DE AQUINO. Suma teológica. São Paulo: Loyola, 2001. p. 69-102.

PLATÃO. A República. Trad.: Carlos Alberto Nunes. Belém: EDUFPA, 2000.

REALE, Giovanni; ANTISERI, Dario. História da filosofia volume 02: Patrística e Escolástica. São Paulo: Paulus, 2009.

TESTI, Claudio A. Pagan Saints in Middle-earth. Zurich: Walking Tree Publishers, 2018.

TOLKIEN, John Ronald Reuel. O Senhor dos Anéis. São Paulo: Martins Fontes, 2001.

TOLKIEN, John Ronald Reuel. The Lord of The Rings. $\mathbf{5 0}^{\text {th }}$ anniversary edition. London: Harper Collins Publishers, 2005.

TOLKIEN, J. R. R.; CARPENTER (org.) Humphrey. As Cartas de J. R. R Tolkien. Curitiba: Arte e Letra, 2006.

TOLKIEN, John Ronald Reuel. On fairy-stories. In: ANDERSON, Douglas A.; FLIEGER, Verlyn (ed.). Tolkien on fairy-stories. London: HarperCollins, 2014. p. 27-84.

TOLKIEN, J.R.R. Sobre Estórias de Fadas. In: Árvore e Folha. Tradução Reinaldo José Lopes. Rio de Janeiro: HarperCollins Brasil, 2020

TOMÁS DE AQUINO. Suma teológica. Coordenação da tradução de Carlos-Josaphat Pinto de Oliveira. São Paulo: Loyola, 2001. Edição bilíngue latim-português.

USARSKI, Frank. Constituintes da Ciência da Religião. São Paulo: Paulinas, 2006.

Submetido em: 4-6-2021

Aceito em: 11-10-2021 